\title{
Which aspects of health differ between working and nonworking women with fibromyalgia? A cross-sectional study of work status and health
}

\author{
Annie Palstam ${ }^{1 *}$, Jan L Bjersing ${ }^{1,2}$ and Kaisa Mannerkorpi ${ }^{1,3,4}$
}

\begin{abstract}
Background: Women with fibromyalgia (FM) describe great difficulties in managing work. Reported work ability in women with FM varies from 34 to 77 percent in studies from different countries. Many factors are suggested to affect the ability to work in women with FM, including pain, fatigue, impaired physical capacity and activity limitations. However, it is difficult to define to which extent symptom severity can be compatible with work. The aim of this study was to investigate which aspects of health differ between working women with FM and nonworking women with FM.

Methods: A cross-sectional study of 129 women of working age with FM which included clinical assessment, structured interviews, questionnaires and performance-based tests. The women were categorized as working or nonworking. Aspects of health are presented according to the International Classification of Functioning, Disability and Health (ICF).

Results: Working women with FM presented better health than nonworking women with FM in ratings of body function (FIQ pain $p<0.001$, FIQ fatigue $p=0.006$, FIQ stiffness $p=0.009$, HADS-Depression $p=0.007$ ). Ratings of overall health status were also significantly better in working women with FM than in nonworking women with FM (FIQ total, eight-item $p=0.001$ and SF-36 PCS $p<0.001$ ). No significant differences were found between workingand nonworking women in tests of physical capacity. FIQ pain was an independent explanatory factor for work in stepwise multiple logistic regression analysis (OR 0.95, Cl 0.93-0.98), $p<0.001$.

Conclusion: Working women with FM reported better health than nonworking women with FM in terms of pain, fatigue, stiffness, depression, disease specific health status and physical aspects of quality of life, which represent body functions and overall health status. However, they were equally impaired in tests of physical capacity.

Moderate pain levels were compatible with work, while severe pain appeared to compromise work. Fatigue was better tolerated, as women scoring severe levels of fatigue worked.
\end{abstract}

Keywords: Fibromyalgia, Work, Health, Women, Physical, Pain

\section{Background}

The research criteria of fibromyalgia (FM) as defined by the American College of Rheumatology (ACR) criteria for FM include a history of widespread pain for at least three months and pain on manual palpation in 11 of 18 tender points [1]. FM is characterized by persistent widespread pain, increased pain sensitivity and tenderness [1].

\footnotetext{
* Correspondence: annie.palstam@gu.se

'Department of Rheumatology and Inflammation Research, Institute of Medicine, Sahlgrenska Academy, University of Gothenburg, Gothenburg, Sweden

Full list of author information is available at the end of the article
}

Other associated symptoms are fatigue, psychological distress [1,2], activity limitations [3] and impaired physical capacity [4]. The prevalence of FM ranges from 1 to $3 \%$ in the general population, it is more common among women and increases with age [2,5].

Activity limitations in FM have an impact on work ability [6]. FM imposes a heavy patient burden in terms of disability, loss of quality of life and costs, and it imposes an economic burden on society [7]. The degree of employment in FM varies geographically, with a range from $34 \%$ to $77 \%$ in different studies [8]. The wide range

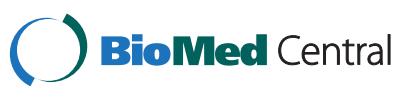


is related to differences in the social benefit systems and labour markets of different countries [8]. Working women with FM have previously been reported to experience less pain, less fatigue and better functional status than nonworking women with FM [9]. Severe pain and fatigue combined with a demanding life situation and ageing have been associated with work disability in FM, as well as self rated disability and unmarried status $[10,11]$.

Disability benefits in Sweden are approved when a disease impairs a person's ability to work by at least $25 \%$. Approximately $72 \%$ of all women in Sweden of working age (16-64 years) were employed in the year 2005 and $8 \%$ received full-time disability benefits ${ }_{1}$.

Interview studies have indicated that the severity of symptoms and psychosocial and environmental factors influence work disability in women with FM [3,8,11-14]. These findings are supported by results of surveys conducted in large populations $[6,10]$. However, it is difficult to define to which extent symptom severity can be compatible with work. Assessments of physical, social and psychological health components combining subjective ratings with performance-based tests would advance our understanding in this area.

\section{Objective}

The purpose of this study was to investigate which aspects of health differ between working women (WW) with FM and nonworking women (NWW) with FM. We hypothesized that WW with FM would display better health than NWW with FM in terms of subjective ratings of health and performance-based tests of physical capacity.

\section{Methods}

\section{Study design}

A cross -sectional study of work status and health in women with FM.

\section{Participants}

Women with FM were recruited to an experimental study [14] from three primary health-care centres in West Sweden by systematic search of patient journals and by consecutive recruitment. The inclusion criteria were women who were 18-60 years of age and suffered FM according to the American College of Rheumatology (ACR) criteria for FM [1]. The search of patient journals found 298 potentially eligible women who were contacted by post $(n=55)$ or telephone $(n=243)$ for further screening. Forty-eight women could not be contacted, 55 did not meet inclusion criteria at telephone screening, and 61 declined to participate in the study, while 134 agreed to participate in an examination. Twentythree of them did not meet inclusion criteria at examination, 17 were excluded due to; treatment in progress $(n=3)$, severe disorders $(n=9)$ or unemployment $(n=5)$ and 18 declined to participate. At the same time, 93 women were consecutively recruited to the study. Fifty-three of them fulfilled inclusion criteria and agreed to participate in the study. A total of 129 women with FM formed the study population. The study population was divided into two groups according to work status; WW (25-100\%) and NWW (0\%). The WW included 13 full-time workers (80-100\%), 13 part-time workers working less than 50\% (25-49\%), 17 part-time workers working $50 \%$, and 10 part-time workers working $50 \%$ or more (50-75\%). Thirty-seven part-time working women received disability benefits while three did not. All NWW received disability benefits.

\section{Data collection}

Clinical assessments of tender points by manual palpation [1] and muscle tenderness with the Somedic Algometer (Somedic Production AB, Sollentuna, Sweden) [15] were conducted by trained examiners to verify diagnosis according to the American College of Rheumatology criteria for FM [1]. Demographic data including work status were gathered in a standardized interview. The women completed a battery of questionnaires and performed two tests of physical capacity described in detail below. Aspects of health are presented according to the International Classification of Function, Disability and Health (ICF) [16].

\section{Measures}

\section{Personal- and environmental factors}

Information on age, employment, educational level, cohabitation, ethnicity and brief medical history was obtained in a standardized interview. Mean household income per geographical area was based on zip codes and obtained by Statistics Sweden . $_{\text {. }}$

The Fibromyalgia Impact Questionnaire (FIQ) is disease specific and comprises ten subscales of disabilities and symptoms ranging from 0 to 100. A higher score indicates a lower health status [17]. The subscale FIQ feel good is presented as a personal factor according to the ICF [18].

Medical Outcome Study - Social Support Survey fouritem scale (MOS-SSS) is a short version of the 18-item MOS-SSS consisting of a four-item social support scale (1-5) covering four different categories of social support: emotional, tangible, affectionate and positive social interaction. The total score ranges from four to 20. A higher score indicates a higher degree of perceived social support [19].

\section{Body function}

The six-minute walk test $(6 M W T)$ is a performancebased test that measures total walking distance during a 
period of six minutes $[20,21]$. The $6 \mathrm{MWT}$ is considered a useful representation of physical capacity and endurance in daily life [22].

Grippit (AB Detektor, Göteborg, Sweden) is an electronic instrument that measures hand grip force. The mean force over a set period of time (ten seconds) was recorded [20].

Pain localization, this is a self administered sheet that records the number of pain localizations $(0-18)$, based on a drawing of the body with 18 predefined regions [23].

The Fibromyalgia Impact Questionnaire (FIQ) is disease specific and comprises ten subscales of disabilities and symptoms ranging from 0 to 100. A higher score indicates a lower health status [17]. The subscales FIQ pain, FIQ fatigue, FIQ morning tired, FIQ stiffness, FIQ anxiety, and FIQ depression are presented as factors of body function according to the ICF [18].

Hospital Anxiety and Depression Scale (HADS) contains 14 statements, ranging from 0 to 3 , in which a higher score indicates a higher degree of distress. The scores build two subscales: HADS-A for anxiety (0-21) and HADS-D (0-21) for depression. The cut-off score of eight is suggested to indicate possible anxiety and depression [24]. This scale is categorized as a measure of body function since $93 \%$ of its content concerns this ICF domain [18].

Multidimensional Fatigue Inventory (MFI-20) contains 20 statements that build five subscales. Each subscale ranges from four to 20 and a higher score indicates a higher degree of fatigue $[25,26]$. This inventory is categorized as a measure of body function since $67 \%$ of its content concerns this ICF domain [18].

\section{Activity and participation}

The Leisure Time Physical Activity Instrument (LTPAI) is a questionnaire that assesses the amount of time spent on physical activity during a typical week. The total score is the sum of hours of activities [27].

The Fibromyalgia Impact Questionnaire (FIQ) is disease specific and comprises ten subscales of disabilities and symptoms ranging from 0 to 100. A higher score indicates a lower health status [17]. The subscale FIQ physical function is presented as a factor of activity and participation according to the ICF [18].

\section{Health status - elements in overall health status}

The Fibromyalgia Impact Questionnaire (FIQ) is disease specific and comprises ten subscales of disabilities and symptoms ranging from 0 to 100 . The total score is the mean of ten subscales. A higher score indicates a lower health status [17]. Two subscales of the FIQ total score were omitted here (Work missed and Job ability); thus an eight-item total score of the FIQ was applied in the study. FIQ subscales are presented according to ICF [18].

Short-Form 36 (SF-36) is a generic questionnaire that assesses health related quality of life, comprising eight subscales ranging from 0 to 100 . A higher score indicates a better quality of life [28]. The subscales that build two composite scores, the Physical Component Scale (PCS) and the Mental Component Scale (MCS), were used in this study and are presented as health status.

\section{Statistical analysis}

Descriptive data are presented as mean and standard deviation (SD), median and range or the number $(\mathrm{N})$ and percent. The Mann- Whitney U-test was used for analyses of between-group differences in continuous variables. The Mantel Haenzel test and Fisher's exact test were used for analyses of between-group differences in ordinal categorical variables. P-values of $\leq 0.010$ were considered significant. To control possible Type I errors, the upper limit of expected number of false significances for the analyses was calculated by the following formula: $\alpha / 1-\alpha \times$ (number of tests - number of significant tests), where $\alpha$ is the significance level. Variables displaying statistically significant differences in between-group analyses of WW and NWW were included in stepwise multiple logistic regression analysis to evaluate explanatory factors for work. The order of inclusion was based on the level of significance of each variable, where the variable presenting the highest level of significance was included first in the model. An odds-ratio (OR) with 95\% CI is presented for descriptive purposes. The area under the ROC curve (AUC statistics) was calculated for a description of the goodness of explanatory variables.

\section{Ethics}

The study was approved by the ethics committee at the Sahlgrenska Academy, University of Gothenburg. Written and oral informed consent was obtained from all participants.

\section{Results}

\section{Study population}

The mean age was 45.7 years (SD 8.7). The mean duration of symptoms was 10.5 years (SD 7.1). The mean number of tender points was 14.8 (SD 2.4) and the mean pain threshold was $171 \mathrm{kPa} / \mathrm{sec}$ (SD 66). There were no significant differences in pain threshold or the number of tender points between WW and NWW.

\section{Type I error}

The between-group analyses comprised a total of 33 statistical analyses, with 11 significant values at significance level 0.01, and the upper level of number of false 
significances was 0.2 , which indicates that $0-1$ of the significances found might be false.

\section{Personal- and environmental factors}

Personal factors

No significant differences were found between WW and NWW in personal factors.

\section{Environmental factors}

No significant differences were found between WW and NWW in environmental factors (see Table 1).

\section{Body function}

\section{Performance based tests of physical capacity}

No significant differences were found between WW and NWW.

\section{Self rated body function}

The number of pain localizations was fewer in WW than in NWW ( $p=0.009)$ and pain (FIQ pain) was milder in WW than in NWW $(p<0.001)$. Stiffness (FIQ stiffness) was milder in WW than in NWW $(p=0.009)$. Fatigue was less severe in WW than in NWW (FIQ fatigue $p=$ 0.006 , MFI physical fatigue $p=0.001$, MFI reduced activity $p=0.001$ and MFI mental fatigue $p=0.006$ ). WW rated a lower level of depression (HADS-D) than NWW $(p=0.007)$. Fifty-two percent of NWW and $29 \%$ of WW scored above the cut-off score for possible depression.
There was no significant difference in anxiety (HADS-A) between WW and NWW. Fifty-eight percent of the NWW and $47 \%$ of the WW scored above the cut-off score for possible anxiety (8).

\section{Activity and participation}

No significant differences were found between WW and NWW in leisure time physical activity (LTPAI) or activity limitations in daily life (FIQ physical function).

\section{Health status}

A better disease specific health status (FIQ total, eightitem) was found in WW than in NWW $(p=0.001)$. This was also true for physical health related quality of life (SF-36 PCS) $(p<0.001)$ (see Table 2).

\section{Stepwise multiple logistic regression analyses}

Variables displaying a significant difference $(p \leq 0.010)$ between WW with FM $(n=53)$ and NWW with FM $(\mathrm{n}=76)$ were included in stepwise multiple logistic regression analysis. FIQ pain $(\mathrm{n}=128)$ was the only statistically significant variable to independently explain work (OR 0.95, CI 0.93- 0.98), $p<0.001$, (AUC 0.75, CI 0.66- 0.83).

\section{Discussion}

The main finding in this study was that working women (WW) with FM displayed better ratings than nonworking

Table 1 Personal- and environmental factors in working women (WW) and nonworking women (NWW) with fibromyalgia

\begin{tabular}{|c|c|c|c|c|c|}
\hline \multirow[b]{2}{*}{ Personal factors } & \multicolumn{2}{|c|}{$W W(N=53)$} & \multicolumn{2}{|c|}{ NWW $(N=76)$} & \multirow[t]{2}{*}{$p$-value } \\
\hline & Mean (SD) & Median (range) & Mean (SD) & Median (range) & \\
\hline Age, years & $45.4(8.1)$ & $47(22-57)$ & $46.0(9.2)$ & $47(24-60)$ & 0.567 \\
\hline Symptom duration, years & $11.7(5.8)$ & $10(2-24)$ & $9.7(7.9)$ & $8(0.3-45)$ & 0.021 \\
\hline \multirow[t]{2}{*}{ FIQ feel good, 0-100 } & $69.0(28.9)$ & $71(0-100)$ & $81.3(22.7)$ & $86(0-100)$ & 0.014 \\
\hline & $N(\%)$ & & $N(\%)$ & & \\
\hline Living with an adult & $45(84.9)$ & & $55(72.4)$ & & 0.133 \\
\hline Born outside of Sweden & $8(15.1)$ & & $13(17.1)$ & & 0.813 \\
\hline \multicolumn{6}{|l|}{ Education: } \\
\hline$\leq 9$ years & $11(20.8)$ & & $17(22.7)$ & & \\
\hline $10-12$ years & $29(54.7)$ & & $40(53.3)$ & & \\
\hline$>12$ years & $13(24.5)$ & & $18(24.0)$ & & 0.843 \\
\hline \multicolumn{6}{|l|}{ Pharmacological treatment: } \\
\hline Analgesic/NSAID, yes & $31(58.5)$ & & $58(76.3)$ & & 0.035 \\
\hline Psychotropics, yes & $22(41.5)$ & & $37(48.7)$ & & 0.475 \\
\hline Environmental factors & Mean (SD) & Median (range) & Mean (SD) & Median (range) & \\
\hline MOS-SSS, 4-20 & $15.4(4.0)$ & $16(7-20)$ & $14.5(4.1)$ & $15(4-20)$ & 0.267 \\
\hline Mean income in area of residence, 1000 Swedish kronor & $214(30.1)$ & $214(165-299)$ & $201(29.7)$ & $205(123-267)$ & 0.042 \\
\hline
\end{tabular}

P-values of $\leq 0.01$ are considered significant and shown in bold type. 
Table 2 Body function, activity and health status in working women (WW) and nonworking women (NWW) with fibromyalgia

\begin{tabular}{|c|c|c|c|c|c|}
\hline \multirow[b]{2}{*}{ Body function, } & \multicolumn{2}{|c|}{ WW (N = 53) } & \multicolumn{2}{|c|}{ NWW (N = 76) } & \multirow[t]{2}{*}{$p$-value } \\
\hline & Mean (SD) & Median (range) & Mean (SD) & Median (range) & \\
\hline \multicolumn{6}{|l|}{ Performance-based tests } \\
\hline $6 \mathrm{MWT}$, meters & $520(95.6)$ & $524(136-674)$ & $500(75.8)$ & $512(295-686)$ & 0.087 \\
\hline Grippit right hand, Newton & $160.3(67.1)$ & $155(27-323)$ & $146.1(67.6)$ & $160(13-334)$ & 0.284 \\
\hline Grippit left hand, Newton & $158.6(73.2)$ & 155(17-349) & $144.3(65.4)$ & $147(19-319)$ & 0.343 \\
\hline \multicolumn{6}{|l|}{ Body function, ratings } \\
\hline Pain localizations, number & $12.5(3.3)$ & $13(5-18)$ & $14.0(3.2)$ & $14(5-18)$ & 0.009 \\
\hline FIQ pain, 0-100 & $62.5(17.1)$ & $63(26-100)$ & $77.0(17.0)$ & $80(26-100)$ & $<0.001$ \\
\hline FIQ fatigue, 0-100 & $75.4(22.4)$ & $83(15-100)$ & $84.8(17.1)$ & $90(19-100)$ & 0.006 \\
\hline FIQ morning tired, 0-100 & $76.9(20.7)$ & $81(10-100)$ & $83.6(18.9)$ & $89(2-100)$ & 0.017 \\
\hline FIQ stiffness, 0-100 & $64.0(27.6)$ & $75(15-97)$ & $75.6(23.7)$ & $82(10-100)$ & 0.009 \\
\hline FIQ anxiety, 0-100 & $42.1(32.6)$ & $38(0-96)$ & $52.5(35.1)$ & $54(0-100)$ & 0.060 \\
\hline FIQ depression, 0-100 & $39.2(31.7)$ & $32(0-96)$ & $48.5(32.5)$ & $51(0-100)$ & 0.116 \\
\hline HADS-A, 0-21 & $7.5(4.8)$ & $7(1-19)$ & $9.7(5.2)$ & $9(1-20)$ & 0.021 \\
\hline HADS-D, 0-21 & $6.2(2.9)$ & $6(2-15)$ & $8.0(3.9)$ & $8(1-16)$ & 0.007 \\
\hline MFI General Fatigue, 4-20 & $16.8(3.0)$ & $18(9-20)$ & $18.0(2.4)$ & $19(12-20)$ & 0.021 \\
\hline MFI Physical Fatigue, 4-20 & $16.2(3.2)$ & $17(9-20)$ & $18.0(2.2)$ & $19(10-20)$ & 0.001 \\
\hline MFI Reduced Activity, 4-20 & $14.5(3.3)$ & $14(8-20)$ & $16.5(3.5)$ & $17(7-20)$ & 0.001 \\
\hline MFI Reduced Motivation, 4-20 & $9.7(3.1)$ & $10(5-16)$ & $10.9(4.3)$ & $11(4-19)$ & 0.123 \\
\hline MFI Mental Fatigue, 4-20 & $13.5(3.5)$ & $14(5-20)$ & $15.1(4.0)$ & $16(4-20)$ & 0.006 \\
\hline \multicolumn{6}{|l|}{ Activity and participation } \\
\hline LTPAl, hours & $4.5(3.9)$ & $3(1-23)$ & $5.4(3.7)$ & $4(1-18)$ & 0.088 \\
\hline FIQ physical function, 0-100 & $39.8(20.5)$ & $40(3-90)$ & $49.9(23.1)$ & $53(0-100)$ & 0.013 \\
\hline \multicolumn{6}{|l|}{ Health Status } \\
\hline FIQ total, 8-item, 0-100 & $58.7(17.1)$ & $63.5(16-88)$ & $69.3(14.5)$ & $71.3(25-95)$ & 0.001 \\
\hline SF-36 PCS, 0-100 & $32.6(8.0)$ & $33.3(15-48)$ & $27.0(7.0)$ & $27.6(11-46)$ & $<0.001$ \\
\hline SF-36 MCS, $0-100$ & $41.6(12.7)$ & $43(17-68)$ & $36.8(13.4)$ & $37.5(16-64)$ & 0.043 \\
\hline
\end{tabular}

P-values of $\leq 0.01$ are considered significant and shown in bold type.

6MWT: six-minute walk test; FIQ: Fibromyalgia Impact Questionnaire; MFI: Multidimensional Fatigue Inventory; HADS-A and -D: Hospital Anxiety and Depression Scale for - anxiety and - depression; LTPAl: Leisure Time Physical Activity Instrument; SF-36 PCS and MCS: Short Form -36, Physical Component Scale and Mental Component Scale.

Missing values: Grippit $(n=1)$, FIQ Pain $(n=1)$, FIQ depression $(n=1)$, FIQ physical function $(n=2)$, LTPAI $(n=1), 8$-item FIQ total $(8)(n=7)$, SF-36 $(n=3)$.

women (NWW) with FM in terms of pain, fatigue, stiffness, depression, disease specific health status and physical health related quality of life, which represent body functions and overall health status.

Physical capacity did not differ significantly between WW and NWW in terms of performance-based tests (see Table 2) where both groups presented lower capacity than the average population [20,21]. This supports earlier studies showing impaired body function in women with FM $[4,29]$. However, the physical work demands might influence the work ability in persons who have an impaired physical capacity. Earlier studies have reported the importance of the work environment in women with FM $[8,11,13,30-32]$ and in other rheumatic diseases [33].
The number of pain localizations was significantly lower in WW than in NWW and global pain (FIQ pain) was significantly milder in WW than in NWW (see Table 2). The mean pain (FIQ pain) of WW was well above $50(0-100)$, which corresponds to the average pain level in previous studies of FM [34]. Mean pain was above $75(0-100)$ in NWW, which corresponds to the ratings of severely afflicted patients with FM [34]. FIQ pain was found to be the only independent explanatory factor for work in this study. Pain has previously been found to be a critical factor for work in rheumatic diseases $[10,35]$. Our results indicate that women with FM having moderate pain generally could be expected to work. Some women appear to be able to work despite severe pain, which raises the question if there are 
workplace related factors that support their ability to work $[32,36]$. The influence of work related factors on work ability in FM need to be further studied.

Global fatigue (FIQ fatigue) was found to be significantly lower in WW than in NWW as well as physical fatigue (MFI-20), reduced activity (MFI-20), and mental fatigue (MFI-20) (see Table 2). Fatigue has previously been found to be an important factor for work disability in rheumatic diseases [35]. However, our results showed severe global fatigue (FIQ fatigue) with mean ratings of over $70(0-100)$ [34] also in WW, indicating that fatigue might not be a critical factor for work disability.

Depression was rated significantly lower in WW than in NWW in the HADS, assessing depression. This supports the results of an earlier study on work disability in FM reporting the negative impact of depression symptoms on work ability [37].

WW displayed a significantly better disease specific health status (FIQ total, eight-item) than NWW (see Table 2). This supports the results from an earlier study on work disability in FM where the FIQ total score was found to predict work disability [6]. Physical healthrelated quality of life (SF-36 PCS) was significantly higher in WW than in NWW (see Table 2), which is in line with a previous study of FM [38]. However, the quality of life of workers in our population, assessed by SF-36, was very low as compared to a national sample [39]. Impaired health status assessed by SF-36 has earlier been associated with work disability in rheumatoid arthritis (RA) [35], systemic lupus erythematosus (SLE) [40] and musculoskeletal pain [41].

The theory of the healthy worker effect suggests that healthier individuals are more likely to remain in the workforce [42]. On one hand, this agrees well with the results of the present study. On the other hand, work is an important factor for health status in women in general $[43,44]$ and in women with FM [38]. Further studies are needed to explore if working women with FM maintain their health status, or if it deteriorates over time.

The main strength of the present study is the integration of physical, social and psychological assessments including subjective ratings as well as clinical assessments and performance-based tests of physical capacity. About $40 \%$ of the patients in this study worked part-time or full-time which is in line with international reports of work ability in FM [8]. No significant differences were found in age, symptom duration, cohabitation, ethnicity, education, pharmacological treatment, mean income in the area of residence and social support, i.e. personal and environmental barriers or facilitators for health [16]. A limitation of this study is the cross sectional design which does not allow analyses of cause and effect. Also, the specific demands in work were not reported in the study and need further investigation.

\section{Conclusions}

Working women with FM reported better health than nonworking women with FM in terms of pain, fatigue, stiffness, depression, disease specific health status and physical aspects of quality of life, which represent body functions and overall health status. However, they were equally impaired in tests of physical capacity. Moderate pain levels were compatible with work, while severe pain appeared to compromise work. Fatigue was better tolerated, as women scoring severe levels of fatigue worked.

\section{Endnotes}

astatistics, Sweden. Stockholm: SCB 2008; 2011 [updated 2011 May 16] Available from: http://www.scb.se.

\section{Competing interests}

The authors declare that they have no competing interests.

\section{Authors' contributions}

AP participated in the design of the study, performed the statistical analysis and drafted the manuscript. JB participated in the design of the study and helped to draft the manuscript. KM conceived of the study, and participated in its design and helped to draft the manuscript. All authors read and approved the final manuscript.

\section{Acknowledgements}

We thank Anna Ericsson, Lena Nordeman, Maud Arndorw, Mona Lind, Mattias Hjelm and Ann-Kristine Neuman for examining the patients. The statistical advisers were Nils-Gunnar Pehrsson and Aldina Pivodic.

\section{Funding}

This work was supported by The Swedish Research Council, the ALF at Sahlgrenska University Hospital, the Research and Development Council of Göteborg and Södra Bohuslän, Västra Götaland Region, Sweden No financial or non-financial interests exist, which could create a potential conflict of interest with regard to the work.

\section{Author details}

'Department of Rheumatology and Inflammation Research, Institute of Medicine, Sahlgrenska Academy, University of Gothenburg, Gothenburg, Sweden. ${ }^{2}$ Rheumatology, Sahlgrenska University Hospital, Gothenburg, Sweden. ${ }^{3}$ Physiotherapy and Occupational Therapy, Sahlgrenska University Hospital, Gothenburg, Sweden. ${ }^{5}$ Sahlgrenska Academy, University of Gothenburg Centre for Person-centred Care (GPCC), Gothenburg, Sweden.

Received: 15 June 2012 Accepted: 17 November 2012 Published: 14 December 2012

\section{References}

1. Wolfe F, Smythe HA, Yunus MB, Bennett RM, Bombardier C, Goldenberg DL, Tugwell P, Campbell SM, Abeles M, Clark P, et al: The american college of rheumatology 1990 criteria for the classification of fibromyalgia. Report of the multicenter criteria committee. Arthritis Rheum 1990, 33:160-172.

2. Wolfe F, Ross K, Anderson J, Russell IJ, Hebert L: The prevalence and characteristics of fibromyalgia in the general population. Arthritis Rheum 1995, 38:19-28.

3. Henriksson C, Grundmark I, Bengtsson A, Ek AC: Living with fibromyalgia. Consequences for everyday life. Clin J Pain 1992, 8:138-144.

4. Mannerkorpi K, Burchkardt CS, Bjelle A: Physical performance characteristics of women with fibromyalgia. Arthritis Care Res 1994, 7:123-129.

5. Lindell L, Bergman S, Petersson IF, Jacobsson LTH, Herrström P: Prevalence of fibromyalgia and chronic widespread pain. Scand J Prim Health Care 2000, 18:149-153.

6. White KP, Speechley M, Harth M, Ostbye T: Comparing self-reported function and work disability in 100 community cases of fibromyalgia 
syndrome versus controls in London, Ontario: The London fibromyalgia epidemiology study. Arthritis Rheum 1999, 42(1):76-83.

7. Annemans L, Le Lay K, Taieb C: Societal and patient burden of fibromyalgia syndrome. PharmacoEconomics 2009, 27(7):547-559.

8. Henriksson CM, Liedberg GM, Gerdle B: Women with fibromyalgia: work and rehabilitation. Disabil Rehabil 2005, 27(12):685-695.

9. Reisine S, Fifield J, Walsh SJ, Feinn R: Do employment and family work affect the health status of women with fibromyalgia? J Rheumatol 2003, 30(9):2045-2053

10. Wolfe F, Anderson J, Harkness D, Bennett RM, Caro XJ, Goldenberg DL, Russell IJ, Yunus MB: Work and disability status of persons with fibromyalgia. J Rheumatol 1997, 24(6):1171-1178.

11. Sallinen M, Kukkurainen ML, Peltokallio L, Mikkelsson M: Women's narratives on experiences of work ability and functioning in fibromyalgia. Musculoskeletal Care 2010, 8(1):18-26.

12. Löfgren M, Ekholm J, Öhman A: "A constant struggle": Successful strategies of women in work despite fibromyalgia. Disabil Rehabil 2006, 28(7):447-455

13. Liedberg GM, Henriksson CM: Factors of importance for work disability in women with fibromyalgia: an interview study. Arthritis Care Res 2002, 47(3):266-274

14. Mannerkorpi K, Nordeman L, Ericsson A, Arndorw M: Pool exercise for patients with fibromyalgia or chronic widespread pain: a randomized controlled trial and subgroup analyses. J Rehabil Med 2009, 41(9):751-760.

15. Kosek E, Ekholm J, Hansson P: Sensory dysfunction in fibromyalgia patients with implications for pathogenic mechanisms. Pain 1996, 68:375-383.

16. World Health Organization: ICF: international classification of functioning, disability and health. Geneva: WHO; 2001.

17. Hedin PJ, Hamne M, Burckhardt CS, Engström-Laurent A: The fibromyalgia impact questionnaire, a swedish translation of a new tool for evaluation of the fibromyalgia patient. Scand J Rheumatol 1995, 24:69-75.

18. Prodinger B, Cieza A, Williams DA, Mease P, Boonen A, Kerschan-Schindl K, et al: Measuring health in patients with fibromyalgia:content comparison of questionnaires based on the international classification of functioning,disability and health. Arthritis Care Res 2008, 59(5):650-658

19. Gjesfjeld CD, Greeno CG, Kim KH: A confirmatory factor analysis of an abbreviated social support instrument: The MOS-SSS. Res Soc Work Pract 2008, 18:231-237.

20. Nordenskiold UM, Grimby G: Grip force in patients with rheumatoid arthritis and fibromyalgia and in healthy subjects. A study with the Grippit instrument. Scand J Rheumatol 1993, 22(1):14-19.

21. Mannerkorpi K, Svantesson U, Carlsson J, Ekdahl C: Tests of functional limitations in fibromyalgia syndrome: a reliability study. Arthritis Care Res 1999, 12(3):193-199.

22. Brooks D, Solway S, Gibbons WJ: ATS statement on six-minute walk test. Am J Respir Crit Care Med 2003, 167(9):1287.

23. Bergman S, Herrström P, Högström K, Peterson IF, Svensson B, Jacobsson LT: Chronic musculoskeletal pain, prevalence rates, and sociodemographic associations in Swedish population study. J Rheumatol 2001, 28:1369-1377.

24. Herrmann C: International experiences with the hospital anxiety and depression scale - a review of validation data and clinical results. J Psychosom Res 1996, 42:17-41.

25. Smets EM, Garssen B, Bonke B, De Haes JC: The multidimensional fatigue inventory (MFI). psychometric qualities of an instrument to assess fatigue. J Psychosom Res 1995, 39:15-25.

26. Ericsson A, Mannerkorpi $\mathrm{K}$ : Assessment of fatigue in patients with fibromyalgia and chronic widespread pain. Reliability and validity of the swedish version of the MFI-20. Disabil Rehabil 2007, 30:1665-1670.

27. Mannerkorpi K, Hernelid C: Leisure time physical activity instrument and physical activity at home and work instrument. Development, face validity, construct validity and test-retest reliability for subjects with fibromyalgia. Disabil Rehabil 2005, 27:695-701.

28. Ware JJ, Sherbourne C: The MOS 36-item short-form health survey (SF36). I. Conceptual framework and item selection. Med Care 1992, 30:473-483.

29. Góes SM, Leite N, Shay BL, Homann D, Stefanello JMF, Rodacki ALF: Functional capacity, muscle strength and falls in women with fibromyalgia. Clin Biomech 2012, http://dx.doi.org/10.1016/j.bbr.2011.03.031

30. Henriksson C, Liedberg G: Factors of importance for work disability in women with fibromyalgia. J Rheumatol 2000, 27(5):1271-1276.
31. Engström LG, Janson S: Predictors of work presence-Sickness absence in a salutogenic perspective. Work 2009, 33(3):287-295.

32. Bossema ER, Kool MB, Cornet D, Vermaas $P$, de Jong M, van Middendorp $H$, Geenen R: Characteristics of suitable work from the perspective of patients with fibromyalgia. Rheumatology (Oxford) 2012, 51(2):311-318.

33. Yelin E: Work disability in rheumatic diseases. Curr Opin Rheumatol 2007, 19(2):91-96

34. Bennett R: The fibromyalgia impact questionnaire (FIQ): a review of its development, current version, operating characteristics and uses. Clin Exp Rheumatol 2005, 23(5 Suppl 39):S154-S162.

35. Ödegård S, Finset A, Kvien TK, Mowinckel P, Uhlig T: Work disability in rheumatoid arthritis is predicted by physical and psychological health status: a 7-year study from the Oslo RA register. Scand I Rheumatol 2005, 34:441-447.

36. Mannerkorpi K, Gard G: Hinders for continued work among persons with fibromyalgia. BMC Musculoskelet Disord 2012, 13(1):96.

37. Kurtze N, Gundersen KT, Svebak S: The impact of perceived physical dysfunction, health-related habits, and affective symptoms on employment status among fibromyalgia support group members. J Muscoskel Pain 2001, 9(2):39-53.

38. Reisine S, Fifield J, Walsh S, Forrest DD: Employment and health status changes among women with fibromyalgia: a five-year study. Arthritis Rheum 2008, 59(12):1735-1741.

39. Taft C, Karlsson J, Sullivan M: Performance of the Swedish SF-36 version 2.0. Qual Life Res 2004, 13(1):251-256.

40. Baker K, Pope J, Fortin P, Silverman E, Peschken C: Work disability in systemic lupus erythematosus is prevalent and associated with socio-demographic and disease related factors. Lupus 2009, 18:12811288.

41. Atroshi I, Andersson IH, Gummesson C, Leden I, Odenbring S, Ornstein E: Primary care patients with musculoskeletal pain. Scand I Rheumatol 2002, 31:239-244.

42. Li C-Y, Sung E-C: A review of the healthy worker effect in occupational epidemiology. Occup Med 1999, 49(4):225-229.

43. Krantz G, Ostergren PO: Common symptoms in middle aged women: their relation to employment status, psychosocial work conditions and social support in a Swedish setting. J Epidemiol Community Health 2000, 54(3):192-199

44. Dew MA, Bromet EJ, Penkower L: Mental health effects of job loss in women. Psychol Med 1992, 22(3):751-764.

\section{doi:10.1186/1471-2458-12-1076}

Cite this article as: Palstam et al:: Which aspects of health differ between working and nonworking women with fibromyalgia? A cross-sectional study of work status and health. BMC Public Health 2012 12:1076.

\section{Submit your next manuscript to BioMed Central and take full advantage of:}

- Convenient online submission

- Thorough peer review

- No space constraints or color figure charges

- Immediate publication on acceptance

- Inclusion in PubMed, CAS, Scopus and Google Scholar

- Research which is freely available for redistribution 